\title{
1. Why youth culture beats age segmentation when it comes to marketing to young consumers
}

\section{CHAPTER OVERVIEW}

In this chapter, I present the limits of the traditional segmentation by age of the youth market and discuss a new, effective segmentation approach that integrates youth culture instead of age. I also introduce the various definitions of the concept of youth culture to overcome the weaknesses by identifying the typologies of youth cultures that marketing and brand managers can take into account in the segmentation of young people and thus prevent a "myopic segmentation." Examples from different cultural settings and theory boxes are also provided to illustrate and explain why it is important for companies to rethink their segmentation strategies and tools when targeting young consumers.

\section{WHY SHOULD MARKETERS CHALLENGE AGE SEGMENTATION?}

The first questions that come to mind when it comes to youth segmentation are related to the profile of young consumers and the characteristics of their behaviors, the age groups to which they belong, and the way brands are targeting and implementing marketing strategies to attract this youth segment: what do we mean by segmenting young consumers? Are we talking about the kid, the pre-adolescent, the tweens, the adolescent, or the post-adolescent segment? And what about high-school and college students as well as young adults; do they still belong to the youth segment? Should marketers target them as a homogeneous generation such as Generation Y (millennials), Generation Z (post-millennials), or Generation Alpha? These questions highlight the ambiguous and fluctuating nature of the definition of the "young consumer" segment and youth consumption patterns and behaviors that marketers and brands need to consider in the implementation of their segmentation and marketing strategies. 
The definition of youth differs according to different disciplines. Sociology, psychology, cultural anthropology, and marketing scholars use different terms and define the youth group in various ways. The definition of youth can even vary from one study to another published by the same author. It is, therefore, crucial to question the definition of youth and the established segmentation by age range to help marketers in defining effective marketing and segmentation strategies that capture both explicit and implicit features of these young consumers - and in turn provide them with suitable products and services with both tangible (e.g., quality, design, functionality) and intangible (e.g., socialization, symbolism, self-esteem) characteristics, valuable to today's youth cohorts.

Marketers and businesses targeting young consumers should then challenge the well-established "age segmentation" approach by considering a holistic youth marketing approach, which goes beyond the idea that young consumers as individuals belong to a set of segments with homogeneous expectations that can be defined by socioeconomic status (SES) or by physiological criteria such as gender and age.

The limitation related to age segmentation has been highlighted by Batat (2017a), who identified in her research focusing on young consumers the need to distinguish a person's "real age" from the person's "perceived age." What Batat refers to as "biological age" is defined by the chronological age of the individual (real age). However, this is often out of step with an individual's subjective age (perceived age). This is especially true when it comes to the youth group because young people can, at some points and in certain situations, feel older than their real ages and vice versa.

Therefore, the next section explores three main issues, specifically youth conceptualization, cultural impact, and the disciplinary discrepancy underling the limitations related to age segmentation, that marketers and brands targeting young consumers should take into account when rethinking their traditional segmentation approaches.

\section{CONCEPTUALIZING YOUTH: INVESTIGATION OF DEFINITIONAL ISSUES}

This section attempts to question the universal and well-established character of the "youth" figure, which has certainly not been examined in marketing and consumer behavior studies. In doing so, I first take a sociohistorical perspective on the rise of the concept of "youth" to highlight its erraticism, complexity, and the difficulties it raises. Then, I introduce the cultural approach to examine the impact of culture on the construction of youth identity. Finally, the concept of the "digital native" generation will be explored from a marketing and consumer behavior perspective to examine how scholars study young 
people as consumers within today's high-tech consumer society so as to define the main features of youth consumption and attitudes towards brands.

\subsection{The Rise of Youth: A Sociohistorical Perspective}

Adopting several angles by analyzing the multidisciplinary literature rooted in history and psychosociology allows us to clarify the concept of youth: what it is, and what it is not. Although questioning the essence of the way that youth is defined may seem fundamental, the answer is not obvious given the ambiguous nature of this notion, whose definition may change from one discipline to another, from one author to another in the same discipline, or even from one study to another by the same author. The rise and evolution of the concept of "youth" have been affected by various cultural, social, historical, and political factors that have shaped its definition throughout history (Batat, 2010). Although the reality of youth is nowadays widely accepted in our modern societies, when examined more closely, every aspect related to it contributes to giving the concept of youth the appearance of artifice that requires scholars to develop an in-depth comprehension of its historical and social foundations to explain its emergence and evolution across cultures and time.

Thus, age ranges, which classify youth stages into homogeneous segments (e.g., kids, pre-adolescents, adolescents, post-adolescents), distinguish the stages of life and set the boundaries between youth and adult generations, vary over time. Even in terms of physical characteristics, youth is influenced by history. For example, the age when a person matures (puberty) and the norms of child empowerment and emancipation vary from one century to another. As a result, the line between youthhood and adulthood has changed over the course of history, according to eras, social contexts, and cultural settings. To be convinced of this observation, it is only necessary to evoke, even briefly, the evolution of the meaning of "youth" and its representation across history and cultures.

From a historical perspective, authors who have studied youthhood (e.g., Feldman-Barrett, 2018, 2019; Heilbronner, 2008) have found that it appears in literature, explicitly or implicitly, from antiquity. Since then, the concept of youthhood has continued to evolve over time. If the original word "adulescence," already existed in ancient Rome, the analogy ends there. Etymologically, "adulescent" refers to an individual who is in the process of growing and does not include any particular age group.

- In Rome, only young men between the ages of 17 and 30 years were so named, and by no means were they pre-adults or post-adolescents. Thus, these young men acquired citizenship at the age of 17 years old and the right to marry from puberty. A woman, on the other hand, became directly 
"uxor" - that is, a wife - without having to pass through youthhood or the adolescence stage. The use of the term youth then disappears;

- Later, throughout the Middle Ages, the population was divided into children and adults around the natural age of puberty. The terms used to designate young people are, therefore, more frequently linked to belonging to a group or a social class than to an age group (Batat, 2010, 2017a). This evolution clearly shows that youthhood is an indefinite concept, multifaceted, and tough to define from a physiological (age and gender) perspective. If the physical transformations that accompany puberty still mark the onset of transitioning from childhood to adolescence, the same is not true for its upper limit, signaling the transition from youthhood to adulthood, which shows complete ambiguity;

- On the other hand, whereas puberty is universal, and is found in all times, youthhood is a recent phenomenon, specific to Western societies, and appeared in the middle of the nineteenth century. Throughout this period of history, puberty marks the transition from childhood to adulthood. Through learning, a young person is introduced to adult know-how. In fact, the word "youth" itself occurs only occasionally in Latin writings of the Middle Ages to describe very imprecise age groups of people between 15 and 60 years old;

- It was not until the mid-nineteenth century that the word youth appeared in the vocabulary of Western societies to designate young college students who were financially dependent and continuing their education. It was at this time that industrialization boomed and life expectancies increased. Simultaneously, a particular type of attire at this age could distinguish young people from children and adults. However, youthhood was far from being a phenomenon of generation but rather a marker of social class because it still only defined a very small number of individuals belonging to the bourgeoisie. The nobles and the poor, on the other hand, continued to benefit from training acquired through contact with adults through preceptors and supervisors.

- The term "youth" to designate an entire age group of both boys and girls only came into use later in the twentieth century with the generalization of schooling. Indeed, youthhood and schooling are strongly related and evolved together;

Progressively, the structuring of the educational system and the training of an increasing number of young people over longer periods has led to their physical and psychological isolation, facilitating the development of a particular youth culture for each age which, in turn, has reinforced the idea of the particularity of each group. The development of a young and supportive age group reached its peak during the 1960s. Thus, as it is understood today, youthhood 
is a phenomenon that is relatively recent and, in some respects, still evolving: young people in the 1950s did not live in the same way as young people in the 1970s or 1990s and 2000s. However, it is in terms of the psychosocial nature of youthhood that the historical changes are the most marked.

Over the last 200 years, people often started working at young ages and did not have access to education and school that continued until they were 16 years old. Therefore, it is the recent movement of mass schooling of young people, both males and females, that has had major effects on the rise of youth as a unique group of individuals and as a subdivision of Western societies.

From a sociological perspective, the contribution of sociologists such as Philipe Ariès (1973), who is known for his masterpiece Centuries of Childhood, has been important. In his works, Ariès contributed to the definition of youthhood by distinguishing it from childhood and adulthood. Thus, the major contribution of sociology is the shift of the focus on youthhood from a concept linked to a "class effect" to the emergence of a "generational effect." For sociologists, the cultural, historical, and chronological characteristics are considered as main factors in differentiating and defining different stages of life between childhood and adulthood, according to the following logic:

- The childhood stage is characterized by the child who belongs to the mother's world, from birth to adulthood. This stage includes people 7-8 years old. The stage is situated before entering adulthood and before going through the phase of adolescence;

- During the nineteenth century, the figures of the school student and the conscript (a person who is required to join the armed forces of a country) appear;

- Then, adolescence arose from the extension of both schooling and military service, which characterized the nineteenth century. The adolescence stage was still associated with childhood and considered to be the second phase of childhood;

- At the beginning of the twentieth century, youthhood was distinguished from childhood and adolescence and referred to a specific age group and a recognizable population. It is during this era that youthhood became a subject of research in sociology.

In the 1970s, sociologists defined the concept of "youth" and its distinction from adolescence was noticeably emphasized by authors in their studies (e.g., Nielsen and Thing, 2019; Debesse, 1972). Batat (2017a) argues that whereas adolescence is more psychological and physiological, youthhood is considered to be a social construction. As Figure 1.1 shows, in the sociology of youth studies, Roudet (2009) identified five major stages linked to the emergence and evolution of sociological studies that examined young people. 


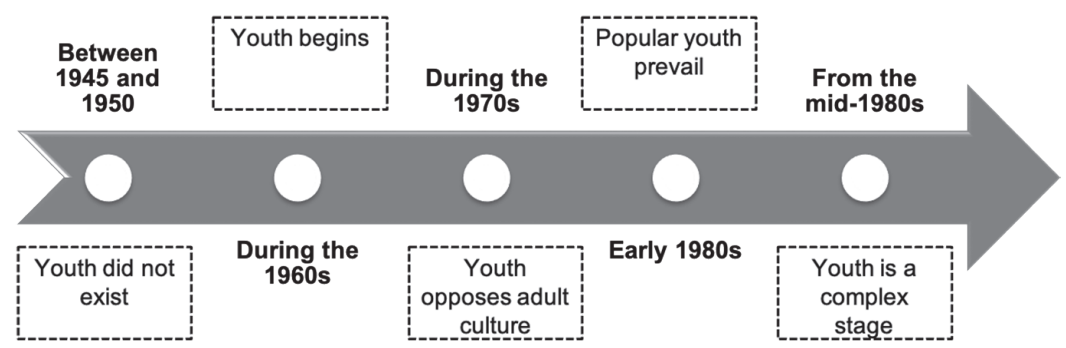

Figure 1.1 The five stages of the rise of youth

Since the 1980s, several studies on youth have been published by scholars in various disciplines, such as anthropology (e.g., Mead, 1935/1963; Rohrer, 2014), educational sciences (e.g., Wortham, 2011), cultural studies (e.g., Buckingham et al., 2015), and marketing (e.g., Batat and Tanner, 2021; Batat, 2008; Roedder-John, 1999). By examining these studies, we can define youthhood as a period of transition into adulthood. This period relates to a process of socialization whereby young people learn to become adults in a society defined by social and cultural rules and norms specific to each society. This definition highlights the crucial role of the cultural facets of age and of youth identity, which go beyond the chronological and physiological notion of one's age range.

Following this definition, it is clear that each age refers to a different identity built around common values and anchored in a specific sociocultural setting (Batat, 2010, 2017a). Thus, youthhood is a social construction defining a social role and a social identity. As a result, youthhood does not refer to individuals with homogeneous behaviors and consumption patterns; rather, it is made up of several heterogeneous youth social realities: pre-adolescence, adolescence, post-adolescence, adulescence, studenthood, active youth, young parents, etc.

Also, in addition to the use of obsolete aspect of age to define youthhood, the American sociologist Parsons (1942) highlighted another difficulty linked to the expansion of the average duration of studies in American society, which has made it harder to define the status of youth. This observation is also accurate in the European context where the age criterion, which determines the youth phase up to the age of 24 years, is no longer acknowledged. Indeed, entering adulthood by getting hired for your first job is no longer the sole criterion of this transition. Several criteria have been identified in demographic studies (Tamesberger and Bacher, 2014) to precisely define the border 
between the youth phase and the entry into adulthood. Among the elements defining the entry into adulthood, four main criteria have been highlighted by demographers:

- Age. This refers to the chronological age at which a young person produces his or her first child. For instance, according to statistics from the National Institute of Demographic Studies (INED, https://www.ined.fr/en/), in 1970, a French woman, on average, bore her first child at the age of 24 versus at the age of 30.3 years today. In the United States, the average age of first-time parenthood increased from 22.7 years in 1980 to 30 or 40 years nowadays, according to the Centers for Disease Control and Prevention (CDC, 2015);

- Couple. This aspect is related to the age at which two individuals start living together and thus form a couple by getting married or cohabiting. Recent statistics reveal that the average age of marriage in Europe increased from 23 years in the 1990 s to 28.5 years in the 2010 s, and 38 years in 2018 . In the United States, the median average increased from 25 years in 1998 to 30 years in 2019 (Statista, 2020);

- The departure from the parents' home and first permanent job. The age of departure has increased and is becoming later and later because of the economic situation and the difficulty newly graduated students are experiencing obtaining their first permanent jobs. This stage has been delayed due to the decrease in steady employment and fixed-term contracts. The average age of a person entering his or her first stable job fell from 26.5 years in the 1990 s to an average of 28 years in the 2010 s;

- The end of the course of education lengthened from 18.3 years in the 1990s to 23 years on average in the 2010 s.

Youth is, therefore, a socially constructed concept and cannot be defined in absolute terms by applying an age principle, or even the aforementioned criteria. Indeed, these four criteria, including age, vary according to the structure and the organization of societies as well as the representations different societies have of youth. For instance, the stage of youthhood may exist in some cultures but not in others for the following reasons:

- The regulation of areas that affect young people's lives, such as schooling, education, or access to employment and housing, can vary considerably from country to another;

- The economic situation is also an additional differentiating factor;

- Historical and cultural factors are also indicators of the multiplicity of youth (e.g., the notion of youth in Northern Europe is different from that in Southern or Eastern Europe). 
Consequently, marketing and communication managers must take into account the "youth experience" of young people according to the context in which they live, instead of using the age criterion to segment the youth population. Recent studies on youth show the existence of instability in youth, which can be progressive depending on two factors: time and space. Sociologist Van de Velde (2008), who analyzed four European countries, identified four forms of "youth experiences" that mark the transition to adulthood:

- The experience of finding oneself refers to the way of living one's youthhood as a long period of exploration and experimentation of one's self and identity. The main objective of this experience is preparing young people's personal development and the definition of their identity on both an individual and social level. This type of youth experience has been identified in Nordic and Scandinavian countries such as Denmark;

- The experience of asserting oneself reflects how young people access individual emancipation and the different paths they take to achieve it. These trajectories are short and mainly centered on the employment search, thus guaranteeing autonomy, independence through self-financing, and the development of individual capacities and skills to navigate within society. This experience of youth has been identified in Anglo-Saxon cultures such as Great Britain and the United States;

- The experience of placing oneself refers to the race for a diploma, which gives access to meaningful work and high social status. Investing in extended schooling and advanced credentials pressures young people to find jobs as quickly as possible and thus exit their youth, which remains rather caricatural (e.g., irresponsible and inexperienced youth). This type of youth experience has been identified in French culture;

- The experience of settling down is very characteristic of Southern European countries, such as Spain or Italy, where young people are looking for a family affiliation, which slows down the departure from their parents' household. The departure is, therefore, conditioned by three main factors: marriage, buying a house, and achieving stable employment.

\section{BACKGROUND BOX 1.1 HOW IS THE YOUTH POPULATION DEFINED IN EUROPE?}

In Europe, the definition of the boundaries of the youth population varies not only according to cultures but also the institutions and the laws that govern each country. Sociologist Van de Velde (2008) examined the process of becoming an adult in the European context by comparing the period of entry into adulthood in different cultures to identify the key features that 
mark this shift. These are as follows:

- In countries such as France, Belgium, Ireland, the UK, and a few Eastern countries, an individual is considered to be part of a youth population until that person gets his or her first full-time job;

- In Scandinavian countries, individuals are considered youth until the day they decide to leave the households of their families;

- In Portugal, Poland, and Bulgaria, young people move into adulthood when they become parents responsible for their own family households.

From a business perspective, defining young people according to "youth experiences" rooted in different cultural settings provides an in-depth understanding of young people's consumption patterns and purchase behaviors and thus is much more relevant than a conventional definition based on the age criterion. The identification of different types of "youth experiences" calls into question the concept of youthhood as a phase or an earlier transitory state inscribed in a logic of "ages of life," in which age ranges are separated from each other by fixed boundaries and disconnected from future behaviors developed and adopted afterwards in adulthood.

Consequently, businesses aiming at young people should approach the youth segment as a cultural fabrication (e.g., Batat, 2017a, 2020; Batat and Tanner, 2021), which is understood from a perspective centered on individuals, their perceptions, expectations, behaviors, and meanings related to the consumption culture to which they belong. This consumption culture is shaped and rooted in a distinct sociocultural, economic, political, environmental, ideological, and technological context.

As a result, the criteria to be used to define youth groups and to segment young people are complex and cannot be limited to biological criteria such as age or the criteria defined by polling institutes (e.g., the age when giving birth to one's first child or obtaining one's first job). If we consider only these criteria related to transitional stages, how can we define and distinguish a young person who has never had children? Or, can we consider in the same way a young 20-year-old student unemployed and living with his or her parents, and a 20-year-old worker who is married and a parent? Are their consumption behaviors, patterns, and practices similar? Do they have the same consumption needs? Do they like the same brands? Do they constitute a homogeneous youth segment with similar expectations? How can brands adopt an appropriate offering and communication approach targeting such individuals?

These questions highlight the limits of the conventional segmentation applied by professionals who target young people by relying on a segmentation of the young population based on age groups with more or less variable limits: 
15-29 years old for some and 11-25 or 10-18 years old for others. To overcome the gaps and ambiguities related to segmenting by age group, marketing and brand managers must rethink their segmentation approaches by adopting holistic thinking, which takes into account cultural and subcultural factors that shape the behaviors and attitudes of young consumers.

\subsection{The Impact of Culture on the Construction of Youth}

Culture is a polysemic notion that encompasses common behaviors and values, acquired and transmitted within a group for multiple purposes, such as cohesion, coordinated action, communication, and adaptation to the environment. Cultures are infinitely complex, with subsystems, such as social organization, language, or family, serving as focal points for observation (Schwartz, 1978; Hall and Jefferson, 1976).

According to Solomon et al. (2010), culture can also be defined as the accumulation of meanings, rituals, norms, and traditions shared among members of a society or organization. Culture includes abstract ideas, such as values and ethics, but also services and material objects, such as cars, clothes, foods, and sports valued by members of the culture. To Hofstede (2001), an iconic figure in intercultural research, culture refers to the collective programming of the mind, which distinguishes the members of one group or category from others.

\section{BACKGROUND BOX 1.2 HOFSTEDE'S FIVE CULTURAL DIMENSIONS}

To define his model, Hofstede relied mainly on an international survey, conducted in 1968 and 1972. The survey examined the attitudes of IBM employees in 72 countries $(n=116,000)$ and identified five major cultural dimensions:

- Uncertainty avoidance refers to the extent to which a society feels threatened by uncertain and ambiguous situations and tries to avoid them by providing greater career stability or establishing more formal rules. Nevertheless, societies in which avoidance of uncertainty is strong are also characterized by a high level of anxiety and aggressiveness, which creates, among other things, a strong internalized need to work a lot;

- Hierarchical distance indicates the extent to which a society tolerates an unequal distribution of power in organizations and institutions. It is also reflected in the values of the less powerful as well in those of the most powerful; 
- Collectivism versus individualism captures a distinction between a tight social fabric, where people clearly distinguish those who are members of the group and those who are outside, and wait for their group (e.g., tribes, organizations) to take care of them in return for their loyalty (collectivism), and a social fabric where people are supposed to take care only of themselves and their immediate families (individualism);

- Masculinity versus femininity corresponds to the dominant values in a society. For example, masculine traits include the go-getting temperament and the taste for money and material goods, in contrast to a preoccupation with others or quality of life (the so-called "feminine" values);

- Long-term orientation measures the orientation towards the future, the present, or the past of a society (Hofstede, 2001, p. 354).

The advantages of the Hofstede model are widely recognized, such as its wide geographic coverage, its robustness, its rigor in research design, and its simple application in studies. Nevertheless, several researchers express reservations criticizing the method of the survey and the outdated aspects of the data. The scientific debate remains open on this subject, but the defenders of the model are more numerous, and many elements converge towards its validity.

Drawing on the conclusions of prior studies, we can distinguish cultures with a rich or poor context and examine them according to their temporal system, and distinguish between monochronic and polychronic cultures (Hall, 1956, 1976). While monochronic cultures tend to assign sanctity to organization, in a polychronic culture everything seems to constantly fluctuate, especially plans for the future. For example, whereas scheduling dominates the professional, social, and even the private lives of individuals in monochronic cultures, establishing precise schedules remains challenging in polychronic cultures. The same is also true in terms of individuals' social and professional interactions.

On the other hand, the GLOBE (Global Leadership and Organizational Behavior Effectiveness) Research Project led by House et al. (2004), which is the largest research project investigating the impact of culture on organizations and society, has conceptualized culture according to cultural dimensions, namely; power distance, uncertainty avoidance, human orientation, institutional collectivism, in-group collectivism, assertiveness, gender egalitarianism, future orientation, and performance orientation. Consequently, one of the major results of the GLOBE project was the identification of ten clusters of countries based on these areas: Eastern Europe, Middle East, Confucian Asia, 
Southern Asia, Latin America, Nordic Europe, Anglo, Germanic Europe, Latin Europe, and Sub-Saharan Africa (for more details see House et al., 2004).

Acquired through a learning process, culture consists of a system of shared values that are invisible and stable over time, and a set of externally visible and evolving practices, such as symbols, heroes, and rituals. Based on these definitions, we can state that values are fundamental elements of cultures, especially when it comes to youth cultures. They are defined as a set of principles guiding young individuals in daily life (Batat, 2014; Roedder-John, 1999) and are related to enduring beliefs acquired and constructed by individuals through exchanges within their socialization processes (Batat, 2008, 2014). Transmitted mainly in childhood by family, but also by the school and the whole society, values are deeply rooted in cultures and change little over time (Hofstede, 2001).

Besides, the domain of the influence of culture can extend over several countries or regions or, on the contrary, be restricted to one country. Likewise, a culture can be divided into ethnic subcultures, such as the Hispanic and Asian subcultures in the United States, or by geography (e.g., southern and northern cultures) or lifestyle (e.g., urban and rural cultures). Following this logic and depending on the cultural setting, individuals' behaviors and practices, especially among the youth segment, are strongly influenced by various cultural factors that can be more or less important according to the significance of their effects on young people's purchasing behaviors, consumption patterns, and attitudes towards brands (Batat, 2014).

Thus, because markets are constituted by people and not products, culture affects consumer behaviors. However, it has been reported that consumers, especially young people, can develop similar behaviors and tastes (Elliott and Cova, 2008) because of their exposure to global ideas and images, as well as their consumption of media culture and social media content. For instance, studies show that in European consumption culture, there is undeniably the emergence of increasingly convergent consumption models for so-called culture-free products (e.g., high-tech and digital products), which are not affected by the local context. The same is true for luxury item consumption, although consumers' motivations can differ depending on whether they belong to an individualist or collectivist culture (Wiedmann et al., 2009).

Analyzing the impact of culture on youth behaviors, studies show that cultural values can be seen as a source of motivation for young consumers within the collectivistic Chinese consumption culture. Indeed, with the economy of the market and social developments in Chinese consumer society, it can be expected that individuals born into this society will acquire consumer values and behaviors that differ from previous generations but are identical to those of young people in individualistic Western societies. Using the work of Hofstede (2001), which highlights cultural values and the typology of cultures (distance 
from power, individual versus collective, male versus female, high versus low uncertainty), Elliott and Cova (2008) show that, unlike Western culture, the fourth dimension of Hofstede's typology (high versus low uncertainty) is difficult to justify in the Chinese context.

Therefore, the results of studies conducted on young consumers in the Western context do not reflect the behaviors of Chinese young people. The cultural values of young Chinese consumers are identical to those of previous generations. Unlike young Westerners, young Chinese consumers strongly embrace collectivistic values because these consumers need security and value compliance and goodwill. Thus, assumptions that the underlying values of young Chinese consumers have altered due to economic changes, the rise of new social trends, and their growing interest in Western products and culture are, therefore, contested. Indeed, Chinese cultural values remain extremely anchored and rooted in the national culture and are, therefore, transmitted from one generation to another, and to today's youth growing up in digital and contemporary societies while resisting changes and globalization.

\section{BACKGROUND BOX 1.3 YOUTH ATTITUDES TOWARDS LUXURY BRANDS IN FRANCE VERSUS CHINA}

Although youth are perceived as a homogeneous group with similar expectations, recent studies emphasize the differences among youth based on cultural and geographical disparities. The comparison of young consumers' attitudes towards luxury brands in two distinct cultural settings, namely France and China, reveals differences between French and Chinese youth in terms of their motivations for consuming luxury products due to their cultural perceptions and definitions of luxury.

In China, luxury goods are considered to be symbols of youth; in France, young people tend to perceive luxury goods both in terms of their symbolic and social values (e.g., the image and social status they project) and their functional aspects (e.g., quality, price, and promotion). At first glance, young Chinese consumers have, on average, less money to spend compared to French youth, although this is also due to the overall level of poverty, which is higher in China. However, among the Chinese living in big cities, many of them are financially comfortable. Due to the one-child policy, the children of wealthy Chinese people benefit greatly from their parents' income. These young people have the opportunity to study abroad and spend money on products they love. They purchase luxury goods to express their identities and styles and share them on social media. Luxury items are symbols of Western culture that allow young people who can afford them 
to demonstrate a higher social status and show their wealth and power in society.

In the French context, the youth population grew up in an economic context characterized by the recession caused by the 2008 financial crisis. They are, therefore, more careful about their spending and do pay attention to the price of products, unlike Chinese youth who grew up in a country that experienced, during the same period, economic growth and increased prosperity. The anxiety about the future, in terms of purchase power, differs in France and China among the youth population. It has been shown that French young people do not believe their incomes will increase in the short term. In contrast, Chinese youth are mostly optimistic about their incomes. This explains why young people in the French context are interested in good deals and promotions. For these people, the price remains a significant factor when it comes to purchasing luxury goods. In addition, French youth are less easily influenced by brands or role models. Thus, the main differences between French and Chinese youth when it comes to luxury consumption and purchases can be summarized as follows:

- Luxury purchasing behaviors. Whereas the purchasing process of French young people is more analytical and rational, young Chinese buyers exhibit impulsive buying behaviors in the purchase of luxury goods;

- Influence of role models (e.g., Instagrammers, ambassadors). Whereas Chinese youth are strongly influenced by the role models and online influencers they follow on their social media, French youth, who also follow influencers, are more analytical and do not necessarily purchase products due to influencers;

- Relationship with luxury. For French young people, purchasing luxuries is considered a dream that might come true or not, depending on their budgets. In the Chinese context, luxury is an obsession, and most youth end up purchasing the items that provide them with social status, and a powerful and attractive image.

Therefore, it remains important for luxury brands to deepen their understanding of the differences among youth populations within different countries, especially because the symbolic aspects of a brand, as a key determinant in the decision to purchase luxury goods is a powerful factor. This is the case among younger Chinese consumers. The Western image, social media influencers, and celebrities have a significant impact on the decision-making process of these buyers. 


\subsection{The Myth behind the Rise of the Digital Native Generation}

Generational segmentation is not new. It is often at the heart of debates involving researchers from different disciplines, governments, and professionals in different sectors, such as tourism, luxury, food, distribution, textiles, leisure, culture, and so forth. For brands and marketers, each new generation raises new questions about transmission, continuity, and disruption in terms of people's social behaviors (e.g., their work habits and management, consumption practices, and daily lives). Since the late 1980s, we have witnessed a behavioral paradigm shift within consumer society accompanied by the emergence of a new youth generation, namely Generation Z (Gen Z), which is characterized by its values and beliefs acquired during its first years of socialization. Additionally, the simultaneous alignment of Gen Z and today's digital era has had a powerful impact that has created a large divide in terms of the values and traits of young consumers who belong to Gen $\mathrm{Z}$ and their predecessors, such as Generation Y, or millennials, and Generation X.

Several researchers who have studied the characteristics of Gen $\mathrm{Z}$ have given this age cohort different names, including the Net or Web generation, post-millennials, Nexters, Generation Next, the Digital Generation, and "digital natives" - a term retained in this section to examine the behaviors and consumption patterns of these young consumers. In some countries, such as Australia, the United States, and the United Kingdom, media and journalists have mainly contributed to the dissemination of the idea of generational differences by highlighting certain behaviors that are specific to digital natives, demonstrating a break from the codes of previous generations.

Although there is a claim of a specificity linked to each term used in the different studies, the authors agree on the common principle that individuals belonging to this generation were born after 2003 (Batat, 2017b). Furthermore, the emergence of this generation is a consequence of the democratization of digital technologies and their integration into the daily lives of a Web 2.0 generation whose members share a common digital culture. Therefore, digital natives belong to a youth generation that is creating a new consumption culture with codes and norms that differ from those of previous generations. Table 1.1 summarizes the birth years and the age groups of different existing generations.

This generational phenomenon highlights the distinctions between generations and creates new opportunities for marketing professionals to develop an in-depth understanding of the consumption characteristics of digital natives, their values, their attitudes, and especially the meanings they assign to their consumption practices and experiences, as well as their perceptions and attitudes towards brands. Indeed, the distinctive and specific characteristics of digital natives could have implications in terms of how this youth generation reacts and creates changes in consumer society. This, in turn, could result in 
a source of innovation for brands that succeed in capturing and sharing the core values of this generation.

Table 1.1 Summary of the birth years and the age groups of the different generations

\begin{tabular}{cc}
\hline Generation name & The age group of the generation in 2020 \\
\hline Silent generation & $78-95$ years old \\
Baby Boomers & $60-77$ years old \\
Generation X & $39-59$ years old \\
Generation $Y$ & $18-38$ years old \\
Generation $Z$ & 17 years old and younger \\
\hline
\end{tabular}

Yet the idea of a homogeneous youth generation gathered under unique features and a common characteristic, namely familiarity with digital technology, has some limitations related to the generational theory used by scholars to define this age cohort. Although focusing on Gen Z, or the digital native generation, is a relevant approach for youth marketing, the concept is fuzzy, and its definition remains superficial and varies from one study to another. Indeed, the concept itself lacks sociohistorical and methodological depth, leading to disparate interpretations, conclusions, and recommendations.

To provide a better definition of the concept, it is essential to retrace the history of the concept via a multidisciplinary approach in order to introduce its implications for the marketing and brand managers targeting today's digital natives, who belong to Gen Z. Let us explore the foundations of the generational theory and examine its limitations.

\subsubsection{Generational theory: a founding principle of digital natives}

The generational theory introduced by Mannheim in 1952 allows both researchers and practitioners to understand and determine cohorts of people according to their belonging to a generation defined objectively by the criterion of the year of birth (Pendergast, 2009). It is a dynamic and sociocultural theoretical framework using a global approach that makes it possible to cover an entire generation, beyond individual characteristics.

This approach defines the generational models that are representative of the characteristics and trends across different generational groups. In this sense, the members of a "living generation" will continue to evolve and often redefine themselves within a predefined time parameter with limited borders. Generational theory, therefore, provides a conceptual framework that allows marketers and brand managers to explore the dimensions of digital native generations and understand the entire youth market beyond the traditional age segmentation. 
Ideas about "generations" and "generational gaps" derived from generational theory are not new but date back to the early 1950s. The sociological approach of Karl Mannheim (1952), as Namer (2006) and Donnison (2007) recall, emphasizes the link that builds a generation (being born within the same period) and the unity of each generation. Mannheim also underscores the acceleration in the rate of appearance of different generations, attributed to the ever-faster succession of changes that characterizes the contemporary era.

Lately, generational theory has found a central place and growing interest in the study of the consumption practices of younger generations (Batat, 2017b; Kjeldgaard and Askegaard, 2006). Considered today as a classic in sociology, Mannheim's work criticizes conventional generational theory, such as the French positivistic and quantitative approach, and highlights the benefits of using a historical and qualitative approach that has German origins. As a result, generational theory has contributed to the definition of youth generations, especially digital natives, who belong to Generation $\mathrm{Z}$ by identifying four key definitional approaches:

- A demographic approach that gathers all individuals who belong to the same age group;

- A genealogical and family approach that includes parents and their children;

- A historical approach that refers to the average time needed for a person to become autonomous and integrated into social and professional life;

- A sociological approach that defines a generational cohort or group of individuals sharing a certain number of practices and representations because they approximately have the same age and thus grew up at the same time.

In addition to these four approaches, Mannheim revolutionized the field of studies on generations by making a major contribution, that consisted in defining three key concepts: the situation of the generation, the generational whole, and the unit of generation (see Table 1.2). These concepts can help scholars and practitioners to better define the sociological dimension of Gen Z consumption practices and behaviors. 
Table $1.2 \quad$ The three major concepts of Generation $Z$

\begin{tabular}{ll}
\hline Concept & Definition \\
\hline $\begin{array}{l}\text { The situation of the } \\
\text { generation }\end{array}$ & $\begin{array}{l}\text { Refers to a "class situation," which puts forward the principle of belonging to the } \\
\text { same historical and social space that goes beyond the chronological aspect. }\end{array}$ \\
$\begin{array}{l}\text { The generational } \\
\text { whole }\end{array}$ & $\begin{array}{l}\text { Can be defined as the participation in the common destiny of a historic and social } \\
\text { unity through the creation of real social bonds between the individuals of the same } \\
\text { generation, who share similar social and intellectual content and interests. }\end{array}$ \\
The unit of & $\begin{array}{l}\text { Refers to a concrete link that reflects the appropriation by individuals of common } \\
\text { experiences within a generational whole. By giving meaning to their common } \\
\text { generation }\end{array}$ \\
& $\begin{array}{l}\text { differentiate themselves from other entities. } \\
\end{array}$
\end{tabular}

\subsubsection{What are the differences among generations?}

Members of a generation share the same interests, beliefs, and values, as well as the same consumption behaviors, regardless of the culture or geographic area. Pendergast (2009) provided a synthesis of the set of values and beliefs that distinguishes each generation, as illustrated in Table 1.3. The classification brings together four main elements:

- Regular trends based on the type of generation (idealistic, reactive, heroic, and artistic);

- The recognition that the formative years of childhood - where there is exposure to a specific set of factors - determine the basic moral values and the belief system of the generation;

- The recognition of the stages of the lifecycle (childhood, young adult, adult, and senior) and consequently the characteristics of each generation at these stages;

- A birth generation is defined by its attributes, which are unique to any given period (e.g., Baby Boomers, Generation X, Generation Y, Generation Z).

\subsubsection{Contributions and limits of generational theory}

Generational theory contributed to the definition of youth cohorts by emphasizing the idea that individuals belong to the same generation not only because they are the same age but also because they have shared experiences that have shaped their lifestyles, consumption patterns, and way of thinking (e.g., the members of a generation who shared the economic crisis in 1929, the subprime mortgage crisis in 2008, or the coronavirus crisis in 2019). In sharing similar experiences, individuals belonging to the same generation define themselves in terms of the characteristics of their timespans and are aware of what differentiates them from previous generations. However, whereas generational theory has been of great use to sociologists and demographers, there are some 
limitations related to the generational segmentation that make it difficult to analyze the behaviors of young consumers as part of a homogeneous digital native generation:

- The first limitation is related to the issue of "generational localization," which reflects the lack of an absolute definition of the year to which each generation belongs and may differ from one researcher to another;

- The second limitation refers to the American origins and cultural influence of the generational concept. For instance, the G.I. generation does not exist in Europe;

- The third limitation concerns the lack of consideration for the social realities of youth cultures.

Table 1.3 The differences between generations

\begin{tabular}{|c|c|c|c|}
\hline Factors & Generation X & Generation Y & Generation Z \\
\hline Beliefs and values & Work ethic, safety & Diversity, freedom & Lifestyle and hedonism \\
\hline Motivations & $\begin{array}{l}\text { Progress and } \\
\text { responsibility }\end{array}$ & $\begin{array}{c}\text { Individuality and } \\
\text { selfhood }\end{array}$ & Self-discovery, relationship \\
\hline Decision making & Authority, brand loyalty & $\begin{array}{l}\text { Experts, informed, } \\
\text { zappers }\end{array}$ & $\begin{array}{c}\text { Friends, less loyalty to } \\
\text { brands }\end{array}$ \\
\hline $\begin{array}{l}\text { Spending and } \\
\text { saving }\end{array}$ & Pay in advance and save & $\begin{array}{c}\text { Credit-savvy, confident, } \\
\text { investors }\end{array}$ & $\begin{array}{c}\text { Uncertain spending, } \\
\text { short-term needs, depends } \\
\text { on the credit }\end{array}$ \\
\hline Types of learning & $\begin{array}{l}\text { Oral, focused on content } \\
\text { and monologue }\end{array}$ & Oral, visual dialogue & Visual and multisensorial \\
\hline $\begin{array}{l}\text { Marketing and } \\
\text { communication }\end{array}$ & Mass & Descriptive, direct & $\begin{array}{l}\text { Participatory, viral, and via } \\
\text { friends and peers }\end{array}$ \\
\hline School education & $\begin{array}{l}\text { In-class, formal, a calm } \\
\text { context }\end{array}$ & $\begin{array}{l}\text { Roundtables, planning, } \\
\text { relaxed atmosphere }\end{array}$ & $\begin{array}{l}\text { Unstructured and } \\
\text { interactive }\end{array}$ \\
\hline $\begin{array}{l}\text { Management and } \\
\text { leadership }\end{array}$ & $\begin{array}{l}\text { Control, authority, and } \\
\text { analytical skills }\end{array}$ & $\begin{array}{l}\text { Cooperation, skills, } \\
\text { actor-makers }\end{array}$ & $\begin{array}{l}\text { Consensual, creativity, and } \\
\text { trial and error }\end{array}$ \\
\hline
\end{tabular}

Source: Adapted from Pendergast (2009).

\section{AGE SEGMENTATION MYOPIA}

Questioning the traditional age segmentation of young consumers is an essential step before defining a suitable and effective marketing strategy targeting the youth segment. Although several youth segmentation methods, which include age as a key criterion, have been proposed by authors in different disciplines and from diverse perspectives (see Table 1.4), the youth segment 
remains very complex and difficult to determine due to young consumers' paradoxical behaviors.

\section{Table $1.4 \quad$ Segmentation approaches of youth populations}

\begin{tabular}{|c|c|c|}
\hline Segmentation & Period & Features \\
\hline $\begin{array}{l}\text { Segmentation in } \\
\text { the Middle Ages }\end{array}$ & $\begin{array}{l}\text { Early childhood stage "infants": 0-6 } \\
\text { years old } \\
\text { Great childhood stage "pueritia": 7-14 } \\
\text { years old } \\
\text { Stage of first adult life: } 15-21 \text { years old }\end{array}$ & $\begin{array}{l}\text { The teenage and youth phases did } \\
\text { not exist. Individuals evolved from } \\
\text { childhood to adulthood. }\end{array}$ \\
\hline $\begin{array}{c}\text { Piagetian } \\
\text { segmentation }\end{array}$ & $\begin{array}{l}\text { Sensorimotor stage: } 0-2 \text { years old } \\
\text { Preparatory stage: } 2-8 \text { years old } \\
\text { Concrete operative stage: } 8-12 \text { years old } \\
\text { Formal stage of operation: } 12 \text { years and } \\
\text { over }\end{array}$ & $\begin{array}{l}\text { Developed by the Swiss psychologist } \\
\text { Piaget in } 1975 \text {, this approach is based } \\
\text { on the stages of cognitive development } \\
\text { from childhood to adulthood. }\end{array}$ \\
\hline $\begin{array}{l}\text { Segmentation } \\
\text { by stage of } \\
\text { socialization }\end{array}$ & $\begin{array}{l}\text { Perceptual stage: } 3-7 \text { years old } \\
\text { Analytical stage: } 7-11 \text { years old } \\
\text { Reflection stage: } 11-16 \text { years old }\end{array}$ & $\begin{array}{l}\text { Developed in } 1999 \text { by Roedder-John, } \\
\text { a researcher specializing in youth and } \\
\text { child marketing. She identified the } \\
\text { developmental stages in the process of } \\
\text { children gradually acquiring knowledge } \\
\text { about consumption. }\end{array}$ \\
\hline $\begin{array}{l}\text { Institutional } \\
\text { segmentation }\end{array}$ & $\begin{array}{l}\text { No schooling: } 0-3 \text { years old } \\
\text { Kindergarten phase: } 3-6 \text { years old } \\
\text { Primary phase: } 7-11 \text { years old } \\
\text { College: } 11-15 \text { years old } \\
\text { High school: } 16-18 \text { years old } \\
\text { University/graduate studies, } \\
\text { apprenticeship/work phase: } 18 \text { years old } \\
\text { and over }\end{array}$ & $\begin{array}{l}\text { This approach is based on } \\
\text { a segmentation method in a local } \\
\text { context, namely, the French school } \\
\text { system, which proposes a breakdown } \\
\text { of the young population according to } \\
\text { the school attended. This segmentation } \\
\text { has the advantage of helping marketers } \\
\text { segment the youth market based on their } \\
\text { knowledge and skills. }\end{array}$ \\
\hline $\begin{array}{c}\text { American } \\
\text { segmentation }\end{array}$ & $\begin{array}{l}\text { Pre-school: } 0-3 \text { years old } \\
\text { Kids: } 3-8 \text { years old } \\
\text { Tweens: } 8-12 \text { years old } \\
\text { Teenager: } 12-17 \text { years old } \\
\text { College students: } 18-23 \text { years old } \\
\text { Young adults: } 23-35 \text { years old }\end{array}$ & $\begin{array}{l}\text { This segmentation is based on the } \\
\text { identification of the social realities of } \\
\text { young consumers and their consumption } \\
\text { behaviors that result from these realities. }\end{array}$ \\
\hline
\end{tabular}

By relying on traditional criteria such as age or socioeconomic status (SES) to segment the youth market, marketing and brand managers risk a myopic segmentation, which can make their positioning strategy obsolete. To define an effective marketing strategy aimed at attracting the youth segment, professionals should not only propose an adapted offering and analyze the competition; it is also important for them to develop an in-depth and holistic understanding 
of the consumption youth culture these young people belong to and assess the norms and codes that shape their behaviors and attitudes towards the adoption or rejection of brands. Indeed, the youth segment is very heterogeneous, and significant differences may exist between different youth cultures and subcultures.

A new segmentation method that takes into consideration the criterion of youth cultures should be implemented by practitioners to avoid myopic segmentation. Instead, the youth market should be segmented following the idea according to which the consumption and purchasing practices of young people are anchored in cultures and subcultures characterized by common codes, symbolic dimensions, meanings, norms, and values shared by the members in each youth consumption culture.

This new segmentation proposal allows us to rethink the relationship that brands and companies have with their young customers by placing more emphasis on the symbolic, emotional, experiential, ideological, sociocultural, hedonic, digital, and functional aspects of their consumption practices. Unlike traditional segmentation by age and other objective criteria, segmentation by consumer "culture" and "subculture" helps companies understand the different meanings young people assign to products, brands, and services.

Therefore, understanding the meaning that young consumers associate with a product or brand will help marketing directors to target youth audiences with suitable offerings, but above all to build loyalty by sharing strong values with them. So how can we define youth cultures? And what are the main youth subcultures companies can consider to adapt their offerings? The next section answers these two questions and provides examples that illustrate the differences among different youth consumption subcultures.

\section{CONSIDERING YOUTH CULTURE: A NEW RULE OF MARKETING TO YOUTH}

Young people nowadays have a great deal of autonomy and are involved in a large number of social and consumption activities. Young people's consumption practices begin at an early age and increase with time. This trend contributes to the individualization of certain consumption practices among young people and the development of different youth cultures and subcultures of consumption. The following discussion will introduce and explain the rise of youth culture in the field of consumption.

\subsection{Defining Youth Culture}

Youth culture or juvenile culture appeared in the 1950s; for the first time an age group of individuals who were "young" massively expressed their interest 
in products within the marketplace, especially cultural products, such as music. These young people displayed distinctive behaviors and exhibited different tastes from those of other generations.

The forms of musical practices were an entire departure from the dominant forms at that time. Thus, cultural activities such as music and movie consumption witnessed the emergence of a specific youth culture. This later opened up the paths to several youthful subcultures, namely the punk, rock, jazz, and rap subcultures. The phenomenon contributed to the consolidation and legitimation of an emerging youth culture by providing it with credibility in terms of purchasing power and the growing influence of these young people in defining future consumption trends within society.

\section{BACKGROUND BOX 1.4 SEVEN COMMON CONSUMPTION FEATURES AMONG FRENCH YOUTH}

Based on the analysis of several studies that examined the lives of young people and their cultural and daily consumption practices, I have identified seven major pillars that characterize common and shared activities and practices among young French people:

1. Listening to music is an essential, even vital, activity in youth cultures;

2. The bedroom culture is a perimeter of freedom for the practice of leisure activities, such as television, video games, surfing the Internet, etc.;

3. Young people attach particular importance to images as well as the visual and aesthetic aspects of their consumption practices;

4. Two modes of travel are important: physical, through the discovery of tourism destinations, and virtual, via the Internet and other cultural activities, such as cinema and reading;

5. In terms of the mode of transport, two-wheel vehicles are a symbol of emancipation from the family home and independence;

6. Creativity, curiosity, and thirst for learning characterize the different youth consumption cultures in France;

7. The rejection of authority. Young people need to assert themselves in a society dominated by rules defined by adults.

Many studies conducted in the 1960s were devoted to analyzing the practices of young people according to the different youth cultures to which they belonged. The examination by different scholars of the concept of youth cultures has helped to broaden the existing sociological models by further 
exploring consumption practices and purchase behaviors within youth cultures and the meanings young people assign to their consumption practices and behaviors according to different youth cultural settings (Batat, 2014, 2017a).

Furthermore, the concept of youth cultures captures the idea that young people not only consume; they also ensure the production of meanings and future trends that are likely to influence other people, for instance, their parents and other individuals.

The common definition of youth culture refers to a form of opposition to the adult world, which produces a dominant culture that young people tend to reject. The British sociologist George P. Murdock, in his examination of the concept of youth cultures in 1965, argues that the opposition of youth to the dominant adult culture can be explained by the desire of young people to get together around a common and shared culture, which offers them a collective solution to the issues linked to the contradictions of a society managed by the rules created by adults.

Youth culture, therefore, provides a social and cultural setting for the development and strengthening of one's self-esteem among young people. In other words, these youthful cultures provide a set of symbols and signs of recognition that youth can use to develop a personal and social identity by adopting consumption practices stemming from their youth culture, such as adopting certain types of music, clothing styles, and eating behaviors. To sum up, youth cultures are mainly described in relation to their capacity to produce meanings and symbols through the acquisition, reinterpretation, manipulation, and especially the reinvention of products' usages and consumption practices.

\section{BACKGROUND BOX 1.5 THE EVOLUTION OF YOUTH CULTURE: A SOCIOHISTORICAL PERSPECTIVE}

The idea of the uniqueness of youth goes hand in hand with the assertion of common consumption practices specific to this population, which evolved rapidly during the twentieth century. We can distinguish three major phases in the development of the global youth culture:

- Post-war youth culture. After the Second World War, young people, and especially those who were students, made their voices heard by engaging in civic youth actions and joining social movements. It is at this moment that societies became aware of the existence of young people who were no longer considered to be children - and their demands. Thus, the image conveyed by the media in the early 1960s portrays youth as a more autonomous, rebellious, and disturbing population. 
- Youth culture, a mimicry of Anglo-Saxon youth. The spread of Anglo-American musical tastes, such as rock music in the early 1960s, influenced youth populations in different countries, especially in European countries. Music has always been part of the identity of young people. They adopt musical styles to express their opinions and identities. The Anglo-Saxon musical style has been acculturated and incorporated into the musical culture of, for example, French young people in the form of yé-yé, which is a style of pop music that emerged from Southern Europe in the early 1960s.

It is, therefore, a culture from elsewhere that distinguishes young people not only from adults and children but also from the rest of society. This culture becomes a generational phenomenon and the youth population is seen as a target market that deserves special attention from cultural industries. At that time, youth culture was regarded as a media culture, which found its origins and inspiration in media content such as radio and television.

- Globalized youth culture. Today, youth culture has become international and globally spread. It is now a question of the Americanization of young people across countries due to the rise of a global economy and the democratization of digital technologies and Internet usages that contribute to creating mass youth cultures, a consequence of the "McDonaldization" of societies. The McDonaldization of society concept was introduced and conceptualized for the first time in 1993 by the American sociologist George Ritzer (1993/1996). Ritzer identified factors for the homogenization of society and the youth culture that is part of it. These factors include fast food, media content, leisure activities, and so on. According to his definition, McDonaldization not only affects the restaurant industry but also education, work, health, travel, leisure, food, politics, and family among other things. Thus, today's young people form a global youth culture comprising a "McWorld" homogenized culture delivered by modern means of communication, information, marketing, and entertainment.

\subsection{From Youth Culture to Youth Subculture}

Youth subcultures bring together individuals who, through their consumption practices, define themselves as distinct from the dominant social norms in the consumption field. The subcultures emerge in collective movements as an action to deal with the lack of necessary resources. These resources are used to achieve objectives defined by the dominant criteria of the social system of 
the middle and upper classes. To illustrate this definition, Table 1.5 presents the characteristics of two youth subcultures in the field of music consumption. The concept of a youth subculture finds its origin in the work carried out by researchers at the Birmingham Centre for Contemporary Cultural Studies (CCCS) located in Birmingham, England. The CCCS developed an approach centered on the emergence of a juvenile subculture and its resistance to capitalist values. CCCS's studies aim to understand the youthful collective behaviors that appear in different subcultures as well as the form of resistance associated with these behaviors.

The definition of the notion of youth subcultures has evolved over time, shifting from a "form of deviance" to a "symbolic and marketing" approach to youth. Table 1.6 provides a summary of the existing definitions of youth subcultures, their forms, their characteristics, and the main authors who contributed to enriching the concept.

Table 1.5 Youth subculture features: rap versus pop rock

\begin{tabular}{|c|c|c|}
\hline Elements & Rap subculture & Pop-rock subculture \\
\hline $\begin{array}{c}\text { Year of } \\
\text { appearance }\end{array}$ & $\begin{array}{l}\text { The 1970s in North America and the } \\
\text { United States; the 1980s in Europe and } \\
\text { France. }\end{array}$ & $\begin{array}{l}\text { The 1960s in the United States, the United } \\
\text { Kingdom, and parts of Europe, and the } \\
\text { 1990s in France. }\end{array}$ \\
\hline Values & $\begin{array}{l}\text { Challenges the elite culture and } \\
\text { promotes street and popular culture. }\end{array}$ & $\begin{array}{l}\text { Rejects traditional values defined by parents } \\
\text { and adults. Emphasizes youth emancipation. }\end{array}$ \\
\hline $\begin{array}{c}\text { Social } \\
\text { dimension }\end{array}$ & $\begin{array}{l}\text { Consists of lower social classes and } \\
\text { often young people with immigrant } \\
\text { backgrounds. In the United States, it is } \\
\text { more about a racial protest movement } \\
\text { against the white music culture. }\end{array}$ & $\begin{array}{l}\text { Considered as a mainstream and commercial } \\
\text { version of real rock, mixing pop and rock. It } \\
\text { is a representation of popular culture in the } \\
\text { middle and upper classes. }\end{array}$ \\
\hline $\begin{array}{l}\text { Subculture } \\
\text { norms }\end{array}$ & $\begin{array}{l}\text { The predominance of masculine values } \\
\text { and the separation of genders. } \\
\text { Tribal and community functioning. } \\
\text { The recent emergence of street rappers. }\end{array}$ & $\begin{array}{l}\text { Challenging institutions, authority, and } \\
\text { dominant norms that govern society to make } \\
\text { young people exist as legitimate actors in } \\
\text { the adult world. }\end{array}$ \\
\hline $\begin{array}{l}\text { Physical } \\
\text { territory }\end{array}$ & $\begin{array}{l}\text { American ghettos and poor } \\
\text { neighborhoods. French suburbs. }\end{array}$ & Urban neighborhoods and peri-urban areas. \\
\hline Clothing style & $\begin{array}{l}\text { Sportswear and comfortable outfits } \\
\text { inspired by the sports market: tracksuits, } \\
\text { caps, sneakers, etc. }\end{array}$ & $\begin{array}{l}\text { A reworked classical BCBG (bon chic bon } \\
\text { genre) style with touches of eccentricity. }\end{array}$ \\
\hline Brands & La Coste, LVMH, Adidas, Nike, etc. & All Saints, Levi's, etc. \\
\hline
\end{tabular}

For companies targeting young consumers, understanding youth subcultures enables them to define effective segmentation strategies and marketing actions that integrate the different forms of consumption subcultures. This requires 
more sophisticated analytical tools to study the significance of both the explicit and implicit characteristics of the consumption practices of young people within different youth subcultures.

\section{Table 1.6 The forms of youth subcultures}

\begin{tabular}{|c|c|c|c|}
\hline $\begin{array}{l}\text { Youth subculture } \\
\text { forms }\end{array}$ & Characteristics & Main authors & Example \\
\hline $\begin{array}{l}\text { Deviance and } \\
\text { transgression }\end{array}$ & $\begin{array}{l}\text { Considered a form of unconventionality and } \\
\text { mental delay. The behaviors of young people, } \\
\text { often from the working class, are considered } \\
\text { as offending acts, which allow them to reach } \\
\text { a high social position. }\end{array}$ & $\begin{array}{l}\text { Burt (1925), } \\
\text { Bowlby (1946), } \\
\text { and Cohen } \\
(1956)\end{array}$ & Gang culture \\
\hline $\begin{array}{l}\text { Subdivision of } \\
\text { a national culture }\end{array}$ & $\begin{array}{l}\text { An assembly of several social realities that } \\
\text { are representative of ethnic background, class, } \\
\text { residence, and religious affiliation forming } \\
\text { a homogeneous unit allowing the segmentation } \\
\text { of the youth population into subsegments. }\end{array}$ & $\begin{array}{l}\text { Gordon (1947) } \\
\text { and Irwin } \\
(1970)\end{array}$ & $\begin{array}{l}\text { Italo-American } \\
\text { youth or } \\
\text { Indian-British } \\
\text { youth }\end{array}$ \\
\hline $\begin{array}{l}\text { Opposition and } \\
\text { resistance }\end{array}$ & $\begin{array}{l}\text { Interdependent subcultures representing a set } \\
\text { of small structures located in a larger cultural } \\
\text { network, and in opposition to the adult culture, } \\
\text { the dominant culture, and the elitist culture. }\end{array}$ & $\begin{array}{l}\text { Hall and } \\
\text { Jefferson (1976) } \\
\text { and Hoggart } \\
(1957 / 1970)\end{array}$ & $\begin{array}{l}\text { British poor } \\
\text { youth in } \\
\text { post-war Britain }\end{array}$ \\
\hline $\begin{array}{c}\text { Identity } \\
\text { construction }\end{array}$ & $\begin{array}{l}\text { An expression of youthful identity through } \\
\text { the same style. Youth subcultures are agents } \\
\text { of socialization that replace families and } \\
\text { educational institutions. }\end{array}$ & Cohen (1972) & $\begin{array}{l}\text { Youth punks in } \\
\text { the UK }\end{array}$ \\
\hline
\end{tabular}

\section{MINI-CASE BOX $1.1 \quad$ TIKTOKERS VERSUS INSTAGRAMMERS: DIFFERENT DIGITAL YOUTH CULTURES?}

TikTok is a video-based social media platform owned by the Chinese company ByteDance. The users on TikTok showcase their creativity by producing short videos and setting trends for other users to follow. These trends could be beauty- or fashion-related or include cooking tips and recipes, funny videos, or anything a person might think of.

In contrast, Instagram is both a photo and video-streaming social media platform owned by Facebook and is much more practical than TikTok. It gives its users more options to surf around the platform, especially through sharing photos. The platform is more emotional and personal than trendsetting TikTok. Why? Because people on Instagram normally share their digital photo albums of their favorite personal moments. 
In terms of each platform's user profile, TikTok's users are mainly members of Gen $\mathrm{Z}$ who are, on average, less than 18 years old. For example, TikTok's influencers include Charli D'Amelio, who had 15 million followers at the age of 15 and now has 105.7 million followers. Its users are attracted to content that is popular, fun, and dynamic, as well as produced by teens for teens.

In contrast, Instagram's users are roughly between 18 and 34 years of age. Millennials, who are in their early twenties and entering adulthood, and Generation Y, the tech-savvy individuals who are always busy are the main users of Instagram. They share photos of their kids, dogs, or whatever they are doing at the moment. The user-friendliness of Instagram, where users merely swipe to see the next post and can tap twice to "like" a post, attracts these busy generations since it is a fast-driven application, and they do not like to wait. This is also similar to TikTok's user-friendliness, where each video posted has its own interface (along with "comments," "likes," and "share" buttons); users also swipe up to see the next post on a different interface.

To conclude, we can see that Instagram's competitiveness in the social media market is growing by the day, locking in all types of users by providing every perk that a social media platform has to offer. Nonetheless, due to TikTok's intensive growth in such a short period (it now has over 1 billion users), Instagram has to up its game.

To analyze the tacit meaning linked to youth behaviors in consumer subcultures, marketing and communication managers should combine several methodological tools. For example, to understand the clothing practices of young people and the link with their subcultures, companies can use a set of qualitative techniques to explore the meanings young people assign to their consumption choices and practices according to the youth subculture's dominant norms and values. These qualitative tools include immersive and exploratory techniques such as:

- Ethnographic tools to understand the codes and norms shared by young people in their consumption subcultures;

- Semiotic tools to analyze the various youth subcultures and the dominant practices that comprise them;

- Historical analysis approaches to understand the evolution of practices, their cyclical dimensions, and the important changes within youth subcultures over time; 
- Phenomenological examination through participant observation of places and areas of consumption that connect, unify, and bring together young people.

Exploratory and immersive studies of youth consumption subcultures are, therefore, vital to fully understand young people and their consumption patterns, and be in tune with them. Young consumers are often skeptical of certain brands and companies and are more likely to mistrust them if they adopt their "own" ways of viewing and defining young people, their values, and what their leisure and consumption practices should be.

Young people's deviation from certain consumption items and brands is a dominant practice in youth subcultures to resist individuals and the entire society and thus affirm their uniqueness and difference within the marketplace; this practice involves the seizure of power by young people, who impose their youth standards, ethical values, and symbolic interpretation on the commercial offer. It is thus a symbolic and creative challenge that leads young people to reject the existing and preconceived offer for them. Deviation practices in youth subcultures represent a social reality as seen and defined by young people that managers must integrate into their offerings and marketing and communication strategies targeting the youth market.

\section{MINI-CASE BOX $1.2 \quad$ E.L.F.: A VEGAN BEAUTY BRAND THAT FITS WITH ETHICAL VALUES OF YOUTH}

e.l.f. cosmetics is a beauty brand that launched in 2004. The brand consists of a wide range of beauty products and cosmetics accessible to all types of people, regardless of what they look like. It is known to be a cruelty-free, vegan beauty brand, attracting consumers from all over the world. It was also one of the first beauty brands to go entirely online, distributing its products to various retailers such as Target, Walmart, Ulta Beauty, and other international retailers.

e.l.f. fulfills the needs of every young individual because it produces cosmetics for any eye shape, lip shape, skin tone, and face. No discrimination is implemented in this brand, making it even more attractive for young beauty fanatics who belong to Gen Z. Gen Z-ers love inclusivity. The fact that the brand is 100 percent vegan scores it more bonus points.

To create a better customer experience for young consumers, e.l.f. has adopted a personalization strategy for its consumers. Ever since the brand closed all 22 of its standalone stores and focused more on distributing its products to retailers such as Target and Walmart, as well as put more effort 
into having a steady online presence, its e-commerce sales have doubled. e.l.f. has personalized the shopping experience of its online customers by carefully studying their behaviors on the website and adjusting the pages they see accordingly. For example, if the user is a new customer, e.l.f. will display all of its products on the homepage; however, if he or she accesses the website again, the site will mainly display similar products to the ones the user clicked on the first time, be it skincare or makeup.

Veganism is the new black, not just in the food and fashion industry, but also in the beauty and cosmetics industry, and Gen $\mathrm{Z}$ is ready for it. e.l.f. has pretty much dominated the vegan drugstore makeup community. No animal ingredients or any animal testing are used to produce e.l.f.'s cosmetics. Animal kindness is considered to be "chic," which is one of the reasons why Gen Z-ers are very interested in this brand. Young people have become more mindful when choosing products. They now focus on how products are made. Just as plant-based foods have been growing in the marketplace, so have plant-based cosmetics in the beauty industry. e.l.f. was one of the beauty brands mentioned by Boots, the UK's leading pharmacy and beauty retailer, in its vegan-friendly statements when explaining its expansion of vegan, plant-based products. This beauty trend is not only growing but it is almost dominating. In fact, Gen $\mathrm{Z}$ beauty consumers have put many luxury beauty brands to shame for not joining the vegan beauty revolution.

\section{KEY TAKEAWAYS}

This chapter shows that developing a relevant segmentation approach targeting young people (children, adolescents, pre-adolescents, and young adults) requires an in-depth understanding of their consumption youth cultures and the codes and norms that govern their purchasing behaviors. Effectively segmenting young people also requires a deep understanding of the differences between various youth consumption subcultures. For companies targeting young consumers, a relevant youth marketing should not be based on age, SES, or gender but rather on the key features of youth cultures that capture both the hidden and explicit meanings young people assign to brands, their consumption activities, and thus, allow firms to decode the paradoxes behind their purchases. 